La categoría «régimen de acumulación»: límites y potencialidades para el estudio de la historia económica argentina. Hacia una propuesta para su reconceptualización

Julieta Almada - Federico Hernán Reche - Sergio Ramiro Saiz Bonzano

páginas / año 11 - n 26 Mayo-Agosto / ISSN 1851-992X/ 2019

http://revistapaginas.unr.edu.ar/index.php/RevPaginas

\title{
La categoría «régimen de acumulación»: límites y potencialidades para el estudio de la historia económica argentina. Hacia una propuesta para su reconceptualización
}

\section{The category "accumulation regime": limits and potentialities for the study of Argentine economic history. Towards a proposal for its reconceptualization}

\author{
Julieta Ayelén Almada \\ Centro de Estudios Avanzados de la Facultad de Ciencias Sociales, \\ Universidad Nacional de Córdoba; \\ Consejo Nacional de Investigaciones Científicas y Técnicas (Argentina) \\ julialmada@gmail.com \\ Federico Hernán Reche \\ Centro de Investigaciones María Saleme Burnichon, \\ Facultad de Filosofía y Humanidades, \\ Universidad Nacional de Córdoba; \\ Consejo Nacional de Investigaciones Científicas y Técnicas (Argentina) \\ rechefederico@gmail.com \\ Sergio Ramiro Saiz Bonzano \\ Facultad de Ciencias Sociales y Facultad de Filosofía y Humanidades; \\ Universidad Nacional de Córdoba (Argentina) \\ s.saizbonzano@gmail.com
}

\begin{abstract}
Resumen
El artículo recupera un conjunto de problemas de orden teórico y metodológico en torno a la categoría «régimen de acumulación» y diferentes interpretaciones a las que ésta ha dado lugar dentro de los estudios sociales argentinos orientados al estudio de la historia económica. En este sentido, se destaca la potencialidad heurística de dicha categoría para el abordaje económico-político situado del conflicto capital-trabajo y se recupera una propuesta para su reconceptualización, que procura superar ciertas limitaciones conceptuales identificadas en las formulaciones hasta el momento existentes.
\end{abstract}

Palabras Clave

Historiografía económica; régimen de acumulación; economía política.

Esta obra está sujeta a la Licencia Reconocimiento-NoComercial-CompartirIgual 4.0 Internacional de Creative Commons. http://creativecommons.org/licenses/by-nc-sa/4.0/ 


\begin{abstract}
The article recovers a set of theoretical and methodological problems around the category "accumulation regime" and different interpretations to which it has given rise within the Argentine social studies oriented to the study of economic history. In this sense, the heuristic potential of this category for the situated economic-political approach of the capital-labor conflict is emphasized and a proposal is recovered for its reconceptualization that tries to overcome certain conceptual limitations identified in the formulations until now existing.
\end{abstract}

\title{
Keywords
}

Economic Historiography; accumulation regime; political economy.

\section{Introducción 1}

Las producciones recientes orientadas a la comprensión de los procesos y transformaciones económicas en Argentina, concentradas especialmente en el período iniciado con la última dictadura cívico-militar, se han apoyado sobre un conjunto de categorías con cierto aire de familia. Entre ellas destaca la de «régimen de acumulación» (RA), que ha sido recuperada por un importante conjunto de investigaciones empíricas con diversas procedencias disciplinares (economía política, sociología económica, historia económica), cuyos problemas se encuentran delimitados en la compleja intersección de lo económico y lo político.

En efecto, la gran mayoría de las propuestas interpretativas en torno a importantes discusiones historiográficas recientes, se encuentran articuladas alrededor de la categoría RA. Es el caso, por ejemplo, de los debates en relación al agotamiento o interrupción de la industrialización sustitutiva; al lugar que le cupo a la última dictadura cívico-militar en el cambio de ciclo; o bien a la caracterización de los años '80 como momento final de un largo proceso de crisis económica y política o, alternativamente, como parte del nuevo régimen de acumulación iniciado a mediados de los años '70. sa, la categoría RA se ha constituido, progresivamente, como una clave heurística recurrente al momento de la periodización y el análisis histórico en un creciente número de trabajos cuyos autores, por otra parte, se inscriben en diferentes tradiciones teórico-políticas.

Sin embargo, esta amplia difusión de la categoría RA no se ha correspondido con un esfuerzo similar orientado a examinar en profundidad su consistencia conceptual, al tiempo que los autores que la recuperan en el medio local tampoco se han

\footnotetext{
${ }^{1}$ Este trabajo recupera discusiones y avances desarrollados en el marco del proyecto de investigación SECyT-UNC "Lo económico y lo político como dimensiones co-constitutivas de la realidad social. Aportes teóricos y metodológicos para el estudio situado del conflicto capital-trabajo en Argentina", dirigido por la Dra. Silvia Morón. Asimismo, agradecemos las observaciones y sugerencias formuladas por dos árbitros anónimos para la corrección del presente artículo.
} 


\section{La categoría «régimen de acumulación»: límites y potencialidades para el estudio de la historia económica argentina. Hacia una propuesta para su reconceptualización}

detenido a realizar precisiones sustantivas sobre su alcance, contenido y extensión. ${ }^{2}$ Muestra de ello es no sólo su divergente nominalización (a veces indistinta al interior de un mismo trabajo), sino principalmente sus diferentes conceptualizaciones como resultado del marco heterogéneo de referencia-en todos los casos sólo parcialmente coincidente-que retoman quienes la utilizan en el medio académico local (v.g. Nun, 1987a y 1989; Neffa, 1996 y 1998; Arceo, 2003; Basualdo, 2001, 2006 y 2010).

Aun bajo esta suerte de dispersión conceptual, cabe destacar que la categoría RA ha dado lugar a contribuciones significativas al interior de los estudios sociales argentinos. Desde nuestro punto de vista ello se vincula con que, a través de ella, se propone visibilizar que lo económico y lo político no designan conjuntos estructuralmente separados de contradicciones: por el contrario, en todos los casos, se busca abordarlas como dimensiones co-constitutivas de la realidad social. Sin embargo, en la medida en fue adquiriendo contenidos y extensiones diferentes dentro de cada programática teórico-política a la que se incorporó, esta categoría ha dado lugar a interpretaciones contrapuestas que, a su vez, cristalizan en periodizaciones igualmente divergentes.

En este marco, nos detendremos aquí en las principales formulaciones existentes de la categoría RA, mediante el análisis de los desplazamientos que en ésta han producido sus diversos contextos de delimitación y operativización. Desde allí, y en función de ciertas limitaciones conceptuales identificadas, presentaremos un conjunto de estrategias de investigación que permitirían aportar mayor rigurosidad teórico-metodológica a la categoría RA y orientar una propuesta de (re)conceptualización que la potencie como herramienta analítica consistente para el estudio históricamente situado del conflicto capital-trabajo, contribuyendo de este modo al abordaje crítico del vínculo co-constitutivo entre lo económico y lo político en los estudios históricos.

Para ello, el artículo se propone dar cuenta de la existencia de un conjunto de categorías con cierto parecido de familia que han organizado múltiples interpretaciones y periodizaciones al interior de la historia económica de la argentina reciente, algunas de las cuales han devenido dominantes en el campo historiográfico; presentar elementos para una crítica conceptual de la categoría «régimen de acumulación», a partir del análisis del modo en que dichas interpretaciones -y sus periodizaciones derivadas- acaban reproduciendo la escisión entre lo económico y lo político; y por último, delinear las estrategias de análisis que creemos necesarias desarrollar a fin de elaborar una reconceptualización de la categoría.

\footnotetext{
2 Entre los pocos trabajos que la abordan específicamente se encuentran Basualdo (2007 y 2019), junto a Schorr y Wainer (2017). Asimismo, entre los aportes formulados en una clave similar a la que organiza la presente contribución, cabe mencionar aquí el de Nogueira (2010).
} 


\section{La categoría «régimen de acumulación» y sus parecidos de familia}

En el contexto de la crisis capitalista de los años '70 y al tiempo que la tradición neoliberal alcanzaba posiciones hegemónicas en los ámbitos académicos e institucionales, dentro de la teoría social se desarrollaron un conjunto de perspectivas críticas articuladas en torno a la necesidad de explicar la capacidad de recomposición del modo de producción capitalista, considerando que las crisis recurrentes a las que se enfrenta son constitutivas de su propia dinámica y se generan por factores esencialmente endógenos. Desde allí, preocupados por aprehender el carácter socialmente estructurado de la acumulación capitalista, estos enfoques propusieron diversas maneras de (re)vincular lo económico y lo político en el abordaje de situaciones históricas concretas, construyendo para ello nuevos entramados conceptuales. Es al interior de este esfuerzo donde se inscribe el desarrollo de diversas categorías analíticas de alcance medio que posibilitan periodizar y analizar el devenir histórico-económico de las sociedades contemporáneas, tales como «modo de desarrollo», «modo de regulación», «régimen de acumulación», «estructuras sociales de acumulación», «modo de acumulación», «estrategias de acumulación» (Aglietta, [1976] 1986; Boyer, [1986] 1989; Gordon, Edwards y Reich, 1982; Jessop, 1983).

Dentro de este conjunto, la categoría «régimen de acumulación» (RA) ha cobrado singular relevancia en la actualidad al interior de los estudios sociales argentinos, en particular orientando la periodización y el análisis de la historia económica. No obstante, tres elementos destacan en relación al modo en que ésta es recuperada por un extenso conjunto de trabajos.

En primer lugar, dicha categoría se presenta bajo múltiples y divergentes nominalizaciones. Así, aunque su uso más extendido la refiere como «régimen de acumulación», tal como fuera especificada por el regulacionismo parisino (Neffa, 1998; Boyer y Neffa, 2004), esta categoría fue introducida en el medio académico local por José Nun (1987a y 1987b) designándola como «régimen social de acumulación». Por su parte, otro conjunto relevante de producciones la presentan indistintamente como «modo de acumulación», "patrón de acumulación» o "régimen de acumulación» (Arceo, 2003; Basualdo, 2001, 2007 y 2010).

En segundo lugar, cabe destacar que existen diferentes trabajos en los que dicha categoría es referida indistintamente -a modo sinonímico- bajo todas las formas que hemos presentado hasta aquí (v.g. Basualdo, 2006 y 2010), aun cuando cada una de ellas remita a conceptualizaciones cuyo contenido y extensión, así como su entramado teórico de referencia, son sólo parcialmente coincidentes. Esta suerte de dispersión y relativa indeterminación conceptual ha dado lugar, por su parte, a diferentes abordajes críticos de esta categoría y algunas de sus interpretaciones historiográficas derivadas (v.g. Astarita, 2008; Bonnet, 2008; Grigera, 2011 y 2013; Pérez Álvarez, 2013; Sartelli y Kabat; 2016).

Finalmente, en tercer lugar, debe resaltarse que las nominalizaciones señaladas se inscriben en un conjunto categorial más amplio que -aun bajo diferentes 


\section{La categoría «régimen de acumulación»: límites y potencialidades para el estudio de la historia económica argentina. Hacia una propuesta para su reconceptualización}

delimitaciones conceptuales- presenta cierto parecido de familia y organiza un importante número de contribuciones: «modelo de acumulación» (Schorr y Wainer, 2017), «modo de acumulación» (Bonnet, 2015; Piva, 2012 y 2015), «patrón de reproducción de capital» (Osorio, 2014; Constantino y Cantamutto, 2014), «estructuras de acumulación» (Torrado, 1992), «patrón de crecimiento» (Costa, 2010), «modelo de desarrollo» (Svampa, 2011).

Desde nuestro punto de vista, las implicancias de esta múltiple nominalización exceden largamente a una cuestión de nomenclatura o un mero debate terminológico: remiten a la propia densidad conceptual de la categoría RA y, desde allí, se proyectan sobre las interpretaciones historiográficas articuladas a partir de ésta. En particular, ello se ha puesto de manifiesto en las diferencias sustantivas existentes a nivel de la periodización y el análisis de las transformaciones operadas en Argentina a partir de mediados de la década de 1970 entre, por ejemplo, los abordajes de Neffa (1998 y 2008) y Basualdo (2001 y 2010).

\section{Principales conceptualizaciones de la categoría «régimen de acumulación» en los estudios sociales argentinos}

La primera aparición de la categoría en el medio académico local se produjo gracias a José Nun, quien bajo la nominalización «régimen social de acumulación» la introdujo en el primero de los ya clásicos Ensayos sobre la transición democrática en la Argentina (Nun y Portantiero, 1987). ${ }^{3}$ A juzgar por sus referencias al momento de delimitarla, se trata de una hipótesis explicativa propia que fue forjada en el marco del debate en torno a la "transición democrática",4 recuperando aportes de diferentes escuelas anglófonas: la economía radical y sus enfoques de las "estructuras sociales de acumulación", el institucionalismo, junto a los aportes de Jessop en el campo de la teoría política. ${ }^{5}$

\footnotetext{
${ }^{3}$ Reelaboraciones del mismo ensayo pueden consultarse en Nun (1987b y 1989), mientras que la misma definición de la categoría que nos ocupa puede verse en Nun (2001b).

${ }^{4}$ Sobre los debates intelectuales que tuvieron lugar en Latinoamérica entre fines de los '70 y principios de los '80, así como las hipótesis explicativas del "giro democrático" y la programática teórico-política que fue conformándose en torno a la denominada "transición democrática", pueden consultarse los trabajos de Lesgart (2002 y 2004) y Lechner (1982 y 1988). Una sintética reseña de estos en relación a aquellos tópicos puede encontrarse en Saiz Bonzano (2012) y Morón y Caro (2013), que operan como referencia inmediata de las reflexiones que aquí desarrollamos.

${ }^{5}$ En efecto, en todos los trabajos referidos arriba este autor remite a las obras de Gordon, Edwards y Reich (1982), Block (1986) y Jessop (1983) al momento de conceptualizar la categoría «régimen social de acumulación». Con posterioridad, recién en el ensayo de 1989, Nun mencionará al regulacionismo francés señalando que "más recientemente, he tomado conocimiento de las significativas contribuciones de la llamada 'escuela francesa de la regulación', que reserva el nombre de régimen de acumulación para las relaciones económicas y llama modo de regulación al conjunto de instituciones y pautas de conducta que las controlan" (1989: 122, nota 20; cursivas en el original), remitiendo a la lectura de Lipietz. Por último, cabe señalar que Nun reconoce posteriormente el parentesco con la teoría de la regulación y -especialmente- con el enfoque norteamericano de las "estructuras sociales de acumulación", pero se distancia de ambas perspectivas en la medida que, según afirma, le "otorgan un papel determinante a la forma particular de organización del trabajo en
} 
Desde allí, Nun afirma que,

"así como hay un régimen político de gobierno, hay también un régimen social de acumulación, en cuyo contexto operan los agentes económicos. Si la evidencia histórica señala, por un lado, que la producción capitalista es altamente adaptable [...], revela, por el otro, que esta producción exige un marco institucional más o menos estable que la favorezca y, sobre todo, que posea algún nivel mínimo de coherencia" (1987a: 37).

De este modo, nuestra categoría designa aquí el "conjunto complejo de las instituciones y de las prácticas que inciden en el proceso de acumulación de capital, entendiendo a este último como una actividad microeconómica de generación de ganancias y de tomas de decisiones de inversión" (ibíd.; cursivas nuestras). En otras palabras, el régimen social de acumulación refiere a "un proceso histórico pluridimensional de mediano o largo plazo, que define eso que corrientemente se llama una 'etapa' o un 'estadio' capitalista" (39), supone la existencia de mecanismos que coordinan un dilatado espectro de actividades privadas y públicas, al tiempo que articula modos de legitimación que le son propios (v.g. 41).

Por otra parte, Nun resalta lo deliberado de los dos primeros términos -régimen social- en su conceptualización, como un esfuerzo orientado a "exorcizar de entrada cualquier tentación economicista" (36). En una crítica que emparenta a Marx con los economistas clásicos, ${ }^{6}$ Nun rechaza las formulaciones mecanicistas y derivacionistas del problema de la determinación. En este marco, afirma que "la política o la ideología son siempre constitutivas de la economía" (ibíd.; cursivas en el original), para luego proceder a diferenciar la categoría régimen social de acumulación tanto del proceso de acumulación en sí,7 como de la "noción clásica de modo de producción que supone a éste determinado en la última instancia por la economía" (37).

No obstante, debe destacarse aquí que a pesar de aquella insistencia de Nun respecto al carácter constitutivo de lo político-ideológico al interior de los procesos económicos, en el párrafo siguiente vuelve a reinstalar la exterioridad entre lo político y lo económico al puntualizar que "aunque lo engloba, aquel conjunto [el RSA] es, en gran medida, externo a esta actividad", en referencia al proceso de acumulación capitalista (ibíd.; cursivas nuestras). A pesar de esta última

la empresa industrial lo cual suele teñirlos de un economicismo excesivo" (Nun, 2001a: 598; cursivas nuestras).

${ }^{6}$ Ello en la medida que, al decir de Nun, comparten la perspectiva según la cual "los comportamientos de los agentes económicos se agregaban por sí mismos en totalidades coherentes" (Nun, 1987a: 3637).

${ }^{7} \mathrm{Al}$ cual, tal como vimos arriba, pareciera definir en sintonía con la teoría estándar como resultado de opciones individuales a nivel microeconómico. A este respecto, al abordar la "dialéctica de estructuras y de estrategias" -que veremos más adelante-, consideramos significativo que Nun refiera a la fuerza inercial de los marcos institucionales y las imágenes e interpretaciones en las que aquélla se concretiza, en términos de "una particular organización del mercado o una determinada estructura de precios relativos" (1987a: 39-40). 


\section{La categoría «régimen de acumulación»: límites y potencialidades para el estudio de la historia económica argentina. Hacia una propuesta para su reconceptualización}

contradicción sutil, Nun -siguiendo a Polanyi- rechaza el espontaneísmo contenido en las tesis neoclásicas del "equilibrio general", destacando la intervención permanente del Estado -y con él de la política- en la economía, más allá de qué tipo de intervención se trate y cuál sea su direccionalidad. ${ }^{8}$

Por otro lado, la categoría RSA parece haber permitido, dentro de los debates en torno a la denominada "transición democrática", una "salida" teórica a un problema político. ${ }^{9}$ Frente a la derrota política que implicó el terrorismo de Estado para los diversos proyectos de transformación social sobre los que se impuso -y, particularmente, para aquellos intelectuales que los abonaron-, las nociones «régimen político de gobierno» $\mathrm{y}$ «régimen social de acumulación» intentaron delimitar conceptualmente las fronteras entre la economía y la política. La revalorización de esta última, en abierto rechazo a la determinación y las consecuencias políticas que se le atribuyeron en el marco de aquel debate, tomó así la forma de una creciente y vertiginosa autonomización. En ese repliegue conceptual se insertó nuestra categoría, a partir de una relectura -entre tantas- del marxismo al calor de la experiencia histórica. Sin embargo, esta apuesta por la superación del derivacionismo y el instrumentalismo -aquella "dialéctica contingente de estructuras y de estrategias" recuperada por Nun de los trabajos de Jessop- habría acabado por sedimentar, bajo el signo de la autonomía, una relación de exterioridad entre economía y política.

Con posterioridad, la producción desarrollada en torno al Centro de Estudios e Investigaciones Laborales - Programa de Investigaciones Económicas sobre Tecnología, Trabajo y Empleo (CEIL-PIETTE) del CONICET, incorporó en los estudios sociales argentinos la categoría «régimen de acumulación». La traducción vernácula del regulacionismo parisino, encabezada por Julio César Neffa, se propuso "estudiar algunas de las grandes crisis del régimen de acumulación y del modo de regulación en Argentina” (Neffa, 1998: 13). En estos estudios se hace una referencia constante a Aglietta, Lipietz y Boyer al momento de delinear su perspectiva analítica (Neffa, 1998, 2004, 2008; Neffa et al., 2010), al tiempo que se expresan de manera recurrente los vínculos institucionales con el Centre d'Etudes Prospectives et de Recherches d'Economie Mathématique Appliquée à la Planification (CEPREMAP) de París y otras agencias francesas de investigación en las que aquellos se cuentan entre sus principales referentes. ${ }^{10}$ Esta recuperación de la perspectiva

\footnotetext{
${ }^{8}$ Nun se acerca significativamente a los regulacionistas al describir esta intervención del Estado en la economía, en particular precisándola como orientada a "organizar los mercados, los sistemas de moneda y de crédito, la oferta de mano de obra, las relaciones entre trabajadores y empresarios, los servicios de infraestructura, el comercio exterior, las pautas de crecimiento urbano, etc." (ibíd.: 38). ${ }^{9}$ Aquí, el término "salida" se nos presenta como problemático; no obstante, acabamos por utilizarlo a falta de otro que nos exprese con mayor precisión. Asimismo, cabría otra aclaración: nuestra categoría no habría permitido, en sí misma, dicha "salida teórica"; sin embargo, sus implicancias conceptuales la situarían en un punto arquimedeano de la programática teórico-política de la "transición democrática".

10 Nótese que numerosos trabajos de la escuela francesa de la regulación han sido traducidos y editados en nuestro país por el CEIL-PIETTE, en particular la producción de Robert Boyer. Asimismo,
} 
regulacionista ha generado cierto énfasis en el abordaje de las crisis argentinas desde un análisis histórico de media o larga duración, privilegiando el estudio de las diferentes formas institucionales en cada período histórico identificado, sus características y articulación. En efecto, las definiciones teóricas que estructuran esta corriente se apoyan en las precisiones conceptuales del regulacionismo parisino, replicándolas casi textualmente.

En ese sentido, en torno a la perspectiva del CEIL-PIETTE cabe destacar que ésta declina de realizar corrimientos teóricos significativos al interior del enfoque regulacionista parisino; por el contrario, se referencia en su vertiente más institucionalista. Debemos recordar aquí que la llamada Teoría de la Regulación (TR) construyó una serie de herramientas analíticas que -consideradas conjuntamente- asumen la forma de una "teoría de alcance medio": nos referimos a las categorías «modo de regulación» y «régimen de acumulación», cuya articulación da lugar al «modo de desarrollo» (Boyer, 2007). En cuanto a la categoría que nos ocupa, ésta es nominada por la TR como «régimen de acumulación» y refiere a la forma de estabilización dinámica que adopta el modo de producción capitalista: se trata del conjunto de regularidades que aseguran una progresión general y relativamente coherente de la acumulación del capital, permitiendo absorber o posponer las distorsiones o desequilibrios que nacen permanentemente del mismo proceso (Boyer y Saillard, 1996).

Otros intentos de conceptualización de esta categoría en los estudios sociales argentinos que resultan pertinentes mencionar aquí son los formulados por Enrique Arceo y Eduardo Basualdo, cuyos aportes conceptuales, sus síntesis heurísticas y sus propuestas de periodización sobre la historia argentina del S. XX; junto a la prolífica producción de los equipos de investigación que contribuyeron a formar y su sostenida vinculación con distintas organizaciones sindicales, han delimitado una perspectiva analítica específica referenciada hoy en torno al Centro de Investigación y Formación para la República Argentina de la Central de Trabajadores Argentinos (CIFRA-CTA).

Así, sin explicitar las vertientes teóricas de las que abreva, Arceo (2003) señala que un RA debe ser abordado atendiendo al tipo y grado de inserción en la economía internacional, así como a las actividades económicas más dinámicas dentro de la coyuntura en estudio. Desde allí, sostiene que

"las características del modo de acumulación dependen de la estructura económico-social, de las luchas políticas y sociales que

en cuanto a las relaciones institucionales internacionales de aquel Centro, además de las mantenidas con el Consejo Latinoamericano de Ciencias Sociales (CLACSO), destacan las vinculadas a diferentes agencias públicas francesas de investigación: el CEIL-PIETTE es sede de la Red FrancoLatinoamericana de Investigadores sobre Trabajo y Tecnologías, teniendo a su cargo su coordinación; mantiene una relación privilegiada con el Centre de Recherches et Documentation sur l'Amérique Latine (CREDAL), UMR del CNRS y de la Universidad de París III; al tiempo que es la agencia de ejecución de varios convenios firmados por el CONICET con instituciones como el Centre de Etudes et de Recherches sur les Qualifications (CEREQ), el Equipe de Recherche "Travail et Mobilités" de la Universidad de París X y el Centre d'Etudes de l'Emploi (CEE). 


\title{
La categoría «régimen de acumulación»: límites y potencialidades para el estudio de la historia económica argentina. Hacia una propuesta para su reconceptualización
}

\begin{abstract}
fueron conformando esa estructura y de la composición del bloque de clases que deviene dominante y que impone un sendero de acumulación acorde con sus intereses. El lugar central que ocupa la composición del bloque de clases dominante en la configuración del modo de acumulación determina que, una vez consolidado éste, el devenir histórico concreto aparezca ineluctablemente subordinado, en sus grandes rasgos, a las exigencias que plantea su reproducción ampliada, que no son sino el reflejo de la lógica de maximización de beneficios del bloque dominante resultante de sus características y de las condiciones históricas específicas en que se desenvuelve" (ibíd.: 19).
\end{abstract}

El modo de acumulación así configurado aparece, entonces, como el único posible y las modalidades de su desarrollo como inevitables, en la medida que las clases y fracciones no hegemónicas no son capaces de construir el poder ideológico, social y político que altere la correlación de fuerzas existente (ibíd.).

Por su parte, Basualdo (2006) -quien sí da cuenta de un marco heterogéneo de enfoques teóricos de referencia-11 plantea que las transformaciones en los sectores dominantes, en las características y el papel del Estado y en las representaciones políticas, son las diferentes dimensiones de un RA. A su vez, éste importa también cambios en la composición y las modalidades de inserción de los asalariados en el mercado de trabajo y su capacidad de negociación, así como en el grado de heterogeneidad y las modalidades de articulación en la economía de los restantes sectores populares. Desde allí, el RA dominante alude para Basualdo "a la articulación de un determinado funcionamiento de las variables económicas, vinculado a una definida estructura económica, una peculiar forma de estado y las luchas entre los bloques sociales existentes" (2007: 6; cursivas en el original). Un RA importa así para este autor variables económicas que deben presentar una regularidad en su evolución, atendiendo tanto al ritmo de repetición de los fenómenos económicos, como a su dinamismo en relación a la evolución relativa de los agregados económicos o de grandes actividades económicas; junto a un orden de prelación a su interior, una jerarquía interna que vincula su importancia relativa y la relación de causalidad o dependencia que mantienen entre ellas. El comportamiento de las variables económicas se encuentra asociado aquí

"a una determinada estructura económica que si bien expresa los

\footnotetext{
11 Basualdo (2001) recupera el concepto gramsciano de hegemonía a partir de los aportes de Gramsci (1974) y Portelli (1980), mientras que en otro trabajo (Basualdo, 2007) retoma las contribuciones de Poulantzas (1976) y O’Donnell (1984) para profundizar en vínculo entre acumulación, dominación, clases sociales y Estado. En ese mismo texto, refiere también a la matriz insumoproducto -y la formación de bloques sectoriales- desarrollada por Leontief (1985), y a Marx (1975) para la conceptualización de los procesos de concentración y centralización económicas. En cuanto a la categoría que nos ocupa, Basualdo (2006) retoma para su conceptualización a Boyer (1989), Arceo (2003) y Nun (2001b).
} 
avances tecnológicos y de los procesos productivos, todos ellos finalmente se aplican como resultado de las luchas sociales que se entablaron entre el capital y el trabajo e involucran a las diferentes fracciones del capital y los distintos estratos sociales dentro de los trabajadores" (ibíd.: 8).

A continuación Basualdo sostiene, asimismo, que "cada régimen de acumulación es conducido por un bloque de poder específico que articula las distintas fracciones del capital", bloque que no es homogéneo a su interior y donde determinadas fracciones ejercen el predominio económico y la hegemonía política. En ese sentido, expresa que

"no necesariamente ambos atributos se concentran en una misma fracción del capital, sino que generalmente uno está disociado del otro. Es decir, que el predominio económico y la hegemonía política son patrimonio de fracciones del capital diferentes, aunque ambas integran el mismo bloque de poder. El predominio alude a la estructura económica mientras que la hegemonía a la incidencia sobre la dinámica estatal" (ibíd.).

Desde aquí, debe destacarse que si bien la perspectiva del CIFRA renuncia a considerar al Estado como una forma institucional entre otras (al modo del regulacionismo parisino y su traducción vernácula por parte del CEIL-PIETTE), éste permanece como sujeto. De este modo, según nuestra mirada, se instalan nuevamente -aunque en una versión más sofisticada- las contradicciones implícitas en la autonomización de la política, subyacente tanto en los aportes de Nun como en las propuestas regulacionistas. Esta autonomización de la política encuentra sus raíces, para nosotros, en la conceptualización del Estado formulada por Basualdo, quien lo presenta en una primera instancia "como un sujeto social y económico más, que garantiza las relaciones capitalistas de producción, pero está desvinculado tanto de los trabajadores como de los capitalistas" (2007: 8). Desde allí, continúa afirmando -junto con O’Donnell- que aquél

"es el garante de la existencia y reproducción de la burguesía y del trabajador asalariado como clases, ya que ello está implicado necesariamente por la vigencia y reproducción de aquellas relaciones [...] el Estado es el garante del trabajador en cuanto clase, no sólo de la burguesía. Esto entraña -lógica y prácticamente- que en ciertas instancias el Estado sea protector de la primera frente a la segunda. Pero no como neutral, sino para reponerla como clase subordinada que debe vender fuerza de trabajo y, por lo tanto, reproducir la relación social que el Estado garantiza" (O’Donnell cita en Basualdo, 2007: 8).

A pesar de estos señalamientos, quisiéramos no obstante destacar la atención prestada por la perspectiva del CIFRA a las contradicciones y disputas internas al 


\section{La categoría «régimen de acumulación»: límites y potencialidades para el estudio de la historia económica argentina. Hacia una propuesta para su reconceptualización}

capital. Desde nuestra mirada, el análisis diferenciado de sus fracciones se presenta aquí como ineludible y absolutamente necesario, sobre todo para cualquier programática teórico-política que pretenda abordar el conflicto capital-trabajo desde la perspectiva de este último. Sin embargo, debemos señalar que la escasa consideración ofrecida por los autores de este enfoque a dicho conflicto en términos de sus dos actores fundamentales, insoslayable en cualquier interpretación marxista, ha habilitado diferentes cuestionamientos a esta perspectiva.

\section{¿Revinculación de lo económico y lo político en el análisis de la historia económica argentina?}

Este conjunto de categorías con cierto parecido de familia se encuentran presentes en numerosos estudios que, desde hace poco más de una década, han renovado las investigaciones históricas sobre los procesos económicos que han signado la Argentina reciente. Inclusive, las periodizaciones en disputa, en las que se expresan, por ejemplo, las diversas interpretaciones del final de la industrialización sustitutiva, o el papel de la última dictadura cívico-militar como bisagra en la historia económica argentina, expresan múltiples recortes fundamentados en estas categorías.

Efectivamente, la categoría RA asume un papel fundamental en relación con una de las operaciones centrales de la disciplina historiográfica: la de la periodización. Al interior del análisis histórico, periodizar no sólo implica el responder a la adecuación al objeto disciplinar a partir de la delimitación espacio-temporal del problema, sino que también, en el mismo movimiento, supone establecer un principio homogeneizador que otorga unidad a un determinado proceso. En ese sentido, la periodización -tanto en el recorte del objeto como en la organización del relato histórico- es una de las formas más inmediatas en las que interviene la perspectiva analítica del investigador en el análisis de los procesos sociales y, dentro de ellas, corrientemente la menos explicitada.

Al delimitar un proceso histórico a partir de rupturas en la continuidad, toda periodización supone la regularidad de ciertas variables, así como una relación lógica de prelación entre ellas, contenida en la perspectiva analítica, y que permite fundar un principio de causalidad que habilita la explicación histórica. A este respecto, en el análisis de la producción historiográfica sobre la economía argentina, con prescindencia del marco conceptual al que adscriban sus autores, dos elementos resaltan desde nuestro punto de vista. Por un lado, en la inmensa mayoría de los trabajos que exceden el estudio de caso y abordan la media o la larga duración, la periodización se realiza atendiendo a un criterio acontecimental antes que procesual. Más allá de si éste representa lo singular o lo específico -para retomar la distinción realizada por Veyne (1984)-, una fecha, más precisamente un día, inaugura y sintetiza la ruptura. Y aun cuando la periodización toma como referencia 
años, estos expresan, indefectiblemente, un día de esos años: 1943 significa así 4 de junio, 1955 significa 16 de setiembre, 1976 significa 24 de marzo. Por otro lado, en los casos en que el criterio de periodización no remite directamente a la política, lo hace, alternativamente, a la economía. En estas ocasiones, cuando no se alude sin más a la modificación en la tendencia de variables económicas exclusivamente, reaparece el criterio acontecimental bajo la forma de una definición de política económica bajo determinado gobierno.

Aunque el análisis pormenorizado de las regularidades señaladas (periodizaciones que privilegian un criterio acontecimiental y que localizan la discontinuidad en el espacio político o el económico), excede el horizonte del presente trabajo, nuestra indagación se encuentra permeada por preguntas como la siguiente: ¿no opera en estas formas de periodización, veladamente, el problema de la determinación? Pareciera que en el criterio de periodización habita, como expresábamos, una decisión previa no explicitada: es en la política $o$ en la economía, siempre como disyuntiva y nunca como díada, donde los procesos sociales encuentran unidad. La elección de privilegiar uno de esos espacios de la vida social pareciera vincularse, así, a un silencioso principio de jerarquía que funda la causalidad histórica. Por otra parte, ¿no habremos los historiadores naturalizado ciertos criterios para fundamentar nuestras periodizaciones, descuidando la problematización de los supuestos que los fundan? En otras palabras: periodizar es necesario, inmanente a toda operación historiográfica; sin embargo, los criterios a través de los cuales periodizamos no lo son. Si bien debiéramos atender a propiedades inherentes a los objetos con los que trabajamos (su "temporalidad diferencial" para retomar la expresión de Annales), ellas rara vez se manifiestan. Estas problemáticas se presentan también, y de manera recurrente, en los estudios sociales argentinos que sobre la base de la categoría RA analizan y periodizan las transformaciones económicas de la Argentina reciente.

En efecto, hacia mediados de los años `90, la versión vernácula del regulacionismo parisino retomó -en su análisis de la historia económica argentina- las periodizaciones de las lecturas liberales dominantes que centran la crisis terminal del proceso de industrialización por sustitución de importaciones en 1989. A partir de aquí, se desarrollaría un nuevo RA que tomaría vigor en los años ' 90 y que estaría acompañado por una transformación en las formas institucionales que configuran el modo de regulación (Neffa, 1998). Esta identificación de un nuevo RA a partir de 1989 resulta coincidente con el planteo de Nun $(1995,2001$ a), según el cual en los años ' 90 se advierte un nuevo régimen social de acumulación que suplanta aquel que se encontraba en su fase terminal y que expresa su mayor crisis hacia fines de los ' 80 .

Contra este consenso historiográfico, y entre las perspectivas que plantaron una renovación en la periodización, Basualdo (2006) se posiciona recuperando en sus análisis la categoría RA. Ésta le permite desarrollar una fuerte crítica a la periodización hasta entonces dominante, que implicó un verdadero giro en las interpretaciones de, por ejemplo, el papel de la última dictadura cívico-militar. El 


\section{La categoría «régimen de acumulación»: límites y potencialidades para el estudio de la historia económica argentina. Hacia una propuesta para su reconceptualización}

autor centrará su crítica en la idea de agotamiento de la ISI, afirmando que hasta 1976 el ciclo de industrialización en Argentina mostraba signos positivos. Es desde el golpe de estado que se configura un nuevo RA, con la interrupción de la sustitución de importaciones y la implantación de la valorización financiera.

Resulta imposible comprender estas periodizaciones distintas con interpretaciones historiográficas contrapuestas, sin atender a la jerarquización diferenciada de ciertos acontecimientos-bisagra en los propios relatos históricos. Así, para algunos autores, el quiebre que implicó para la realidad argentina la última dictadura cívicomilitar y sus consecuencias en todas las esferas de análisis, tiene supuestos teóricos y políticos radicalmente diferentes de quienes centran las transformaciones en los cambios introducidos exclusivamente por el gobierno menemista. Estas disimiles interpretaciones no pueden sino asentarse sobre jerarquizaciones contrapuestas, al interior de la categoría que ordena la periodización.

Tal como hemos advertido en esta breve presentación, las categorías centrales de las perspectivas analizadas, aunque -parcialmente- productivas en su esfuerzo por restituir el vínculo economía-política, se encuentran atravesadas por una debilidad teórico-metodológica insalvable, derivada de la negación o incorporación acrítica de un abordaje consistente del problema de la determinación. Esto conlleva que dichas perspectivas, tanto en su articulación conceptual interna cuanto, en las interpretaciones históricas resultantes y sus propias periodizaciones, acaben por recaer en una forma solapada aquella escisión, presentando la articulación entre lo económico y lo político como una relación de exterioridad.

\section{Por un nuevo programa de investigación}

Sobre la base del reconocimiento de este conjunto de limitaciones analíticas e inconsistencias conceptuales, presentes en las formulaciones hasta ahora existentes, creemos necesario proponer el desarrollo de un sólido trabajo de indagación que busque sentar las bases para una (re)formulación de la categoría RA. Ello en la medida en que entendemos que el núcleo de su consistencia conceptual radica en el vínculo sintético que ésta permitiría establecer entre las formas de valorización y los conceptos Estado, hegemonía y lucha de clases. La categoría RA puede referir entonces así, a una síntesis económico-política que articularía la relación entre: a) la dinámica estructural dominante de valorización a escala global y aquella vigente al interior de una formación social específica en determinado período, junto a sus articulaciones, contradicciones y crisis endógenas; $b$ ) el proceso de lucha de clases que configuran dicha dinámica a escala nacional, al interior del cual determinado bloque social deviene dominante y logra imponer una direccionalidad específica al proceso de valorización; y c) las modalidades de articulación de los dispositivos estatales que permiten al bloque dominante la reproducción ampliada de sus intereses de manera coherente y estable durante 
cierto período. Bajo estos términos, dentro de formaciones sociales capitalistas, delimitamos conceptualmente entonces al Estado como territorio, objeto y resultado -simultáneamente- de la lucha de clases: una configuración institucional -material y simbólica- conformada históricamente a partir de la disputa estratégica que a su interior libran diferentes clases y fracciones -articuladas como bloques sociales de poder- por la hegemonía; disputa estructurada en torno a la direccionalidad del proceso de acumulación.

Desde aquí, y a partir de la síntesis conceptual que supone, cabe destacar que la potencialidad heurística de la categoría RA radica, para nosotros, en que permite visibilizar -al interior del análisis histórico- que lo económico y lo político no designan conjuntos estructuralmente separados de contradicciones, que se desarrollan a nivel de la producción y la circulación/distribución, respectivamente. Por el contrario, la categoría RA posibilitaría abordarlas como dimensiones coconstitutivas de la realidad social: dimensiones que, aunque analíticamente distinguibles, operan de modo orgánico y concurrente -no lógicamente sucesivo- en el proceso de desarrollo histórico. Entendemos que cobran relevancia aquí los efectos duraderos del proceso de escisión (teórico-política) entre estas dos dimensiones al que contribuyeron diferentes campos disciplinares de las ciencias sociales, en particular la conformación de la economía política clásica y especialmente- la síntesis neoclásica dentro de la teoría económica. En esa medida esta categoría interpela, a su vez, los criterios en los que se funda una de las operaciones fundamentales inherentes al análisis histórico: la periodización (Saiz Bonzano, 2011).

Por otra parte, y en este mismo sentido, creemos que una de las primeras tareas para la restitución del vínculo entre economía y política, consiste en retomar una clave teórico-metodológica de análisis que permita indagar en profundidad y con mayor alcance, a través de una crítica histórico-conceptual, los modos en los que diferentes paradigmas y perspectivas estructuraron -al interior de la economía política- el complejo vínculo entre aquellas dimensiones, para poder disciplinar -con mayor rigurosidad teórica y metodológica- herramientas analíticas consistentes para el estudio históricamente situado del conflicto capital-trabajo.

$\mathrm{Al} \mathrm{mismo} \mathrm{tiempo,} \mathrm{quisiéramos} \mathrm{destacar} \mathrm{que} \mathrm{el} \mathrm{conjunto} \mathrm{de} \mathrm{discusiones} \mathrm{que} \mathrm{aquí}$ proponemos se encuentra atravesado por dos núcleos teóricos principales de la teoría social contemporánea. El primero de ellos refiere a la tensión que mantienen las nociones de estructura y agencia al interior de la teoría social, en el esfuerzo por dotar de un marco de inteligibilidad a las prácticas y los procesos históricos. Por otra parte, el segundo remite a la centralidad del conflicto capital-trabajo en la configuración de las formaciones económico-sociales contemporáneas; con él, y particularmente a partir de lo que ha dado en llamarse la metáfora estructura / superestructura utilizada por Marx ([1859] 1980), una de las formas en que al interior de la tradición marxista se actualizará de manera permanente aquella tensión entre prácticas objetivadas y agencias estructurantes.

En particular, nuestra perspectiva analítica suscribe con el esfuerzo de aquellas 


\section{La categoría «régimen de acumulación»: límites y potencialidades para el estudio de la historia económica argentina. Hacia una propuesta para su reconceptualización}

corrientes de la teoría social contemporánea que han intentado superar tanto el mecanicismo economicista, como el subjetivismo implícito en la autonomización absoluta de la esfera política (Thompson, 1978; Meiksins Wood, 1983; Bourdieu y Wacquant, 2005). Asimismo, al centrar el análisis en el capital en tanto relación social determinante, ${ }^{12}$ consideramos al conflicto entre la producción social y la apropiación privada como la contradicción fundamental de las sociedades contemporáneas (Marx, [1867] 1975).

Sobre la base de estas consideraciones y con el objetivo de (re)formular una categoría con gran potencialidad heurística para el análisis de la historia económica, creemos fundamental desarrollar un abordaje multidimensional estructurado a partir de tres estrategias de investigación: (1) una crítica histórico-conceptual de las "situaciones clásicas",13 orientada a analizar el modo en que los principales paradigmas del campo disciplinar de la economía política construyeron la (des)vinculación entre lo económico y lo político en su aproximación a la realidad social; (2) una crítica conceptual de las categorías centrales que estructuran las principales perspectivas heterodoxas que, en el marco de su cuestionamiento al entramado teórico de la síntesis neoclásica, se propusieron restituir el vínculo economía-política; (3) un análisis comparado de un conjunto de propuestas conceptuales y estrategias metodológicas que, al interior de los estudios sociales argentinos, se conformaron a partir del trabajo de investigación empírica sobre el análisis históricamente situado del conflicto capital-trabajo.

La primera estrategia de investigación planteada, de carácter histórico-conceptual, requeriría realizar una revisión crítica de obras y autores centrales en la historia del pensamiento económico orientada a indagar, mediante el modo en que son formuladas sus categorías económicas principales, cómo se expresa la conflictiva articulación entre lo económico y lo político dentro de estos paradigmas "fundacionales", considerados como teorías sociales.

La segunda estrategia procuraría identificar y problematizar la estructura conceptual de la teoría de la regulación, la economía radical americana y la nueva economía institucional, principales matrices teóricas de referencia de las diversas formulaciones existentes de la categoría RA. Estos enfoques surgieron en la década de 1970 en el marco de la crisis que dio lugar al proceso de reestructuración capitalista, como interpelaciones críticas a los paradigmas teóricos entonces dominantes y, en particular, en confrontación abierta con la centralidad creciente de la síntesis neoclásica al interior de la teoría económica. Como parte de ese esfuerzo

\footnotetext{
12 El sentido en el que recuperamos aquí la categoría determinación y sus problemas derivados coincide con el precisado por Wiliams (1978).

13 Schumpeter utiliza este término como forma de categorizar los desplazamientos paradigmáticos dentro de la historia del pensamiento económico, definiendo a la situación clásica como "el logro de concordancia sustancial tras un largo periodo de pugnas y controversias, la consolidación del trabajo nuevo y original precedente" (1982: 87). Cabe destacar aquí que, tal como lo indica nuestro énfasis en torno a los desplazamientos paradigmáticos, éstas nos interesan por el momento fundacional que importan, antes que por la "concordancia" que expresan.
} 
compartido, interrogándose sobre las causas estructurales de aquella crisis y procurando dar cuenta de la sostenida capacidad de recomposición del modo de producción capitalista frente a su inestabilidad sistémica y sus crisis endógenas, estas tradiciones construyeron diferentes entramados conceptuales orientados a (re)vincular lo económico y lo político en el abordaje de situaciones históricas concretas, construyendo nuevas categorías analíticas que posibilitan periodizar y analizar el devenir histórico-económico de las sociedades contemporáneas, tales como «modo de desarrollo» (Aglietta, [1976] 1986) y «estructuras sociales de acumulación» (Gordon, Edwards y Reich, 1982) o que buscan redefinir lo económico desde su anclaje institucional (North, [1990] 1993). De esta manera, esta segunda estrategia de indagación debería recuperar los esfuerzos realizados por las tradiciones teóricas referidas para repensar las formas de lo económico restituyendo su dimensión política y procurando una aproximación a los alcances de sus postulados teórico-epistemológicos a partir de una crítica conceptual de sus categorías estructurantes.

La tercera estrategia de investigación recuperaría diversos aportes desarrollados por un conjunto de investigaciones empíricas, formuladas al interior de los estudios sociales argentinos y con diversas procedencias disciplinares (economía política, sociología económica, historia económica), cuyos objetos se encuentran delimitados en la intersección de lo económico y lo político. En un abordaje crítico y relacional, el análisis de dichas investigaciones permitiría establecer la posibilidad de articular críticamente un conjunto de propuestas conceptuales y estrategias metodológicas, desarrolladas a partir de las exigencias que impone el análisis históricamente situado del conflicto capital-trabajo.

Creemos que todo ello permitiría, por una parte, indagar en torno al modo en que distintas perspectivas resuelven la vinculación entre lo económico y lo político, en el marco de la operativización empírica de sus categorías analíticas. Por otra parte, posibilitaría dilucidar la densidad conceptual y la potencialidad heurística de éstas, a partir de la consistencia teórico-metodológica de su operativización.

\section{Bibliografía}

Aglietta, M. [1976] (1986). Regulación y crisis del capitalismo. La experiencia de los Estados Unidos. México: Siglo XXI.

Arceo, E. (2003). Argentina en la Periferia próspera. Renta internacional, dominación oligárquica y modo de acumulación. Bernal: Universidad Nacional de Quilmes (UNQ).

Astarita, R. (2008). Crítica de la tesis de la financiarización (documento de trabajo). Recuperado de: www.rolandoastarita.com/doc.html 
La categoría «régimen de acumulación»: límites y potencialidades para el estudio de la historia económica argentina. Hacia una propuesta para su reconceptualización

Basualdo, E. (2001). Sistema Político y modelo de acumulación en la Argentina. Notas sobre el transformismo argentino durante la valorización financiera (1976-2001). Bernal: UNQ.

Basualdo, E. (2006). La reestructuración de la economía argentina durante las últimas décadas de la sustitución de importaciones a la valorización financiera. En E. Basualdo y E. Arceo; Neoliberalismo y sectores dominantes. Tendencias globales y experiencias nacionales. Buenos Aires: Consejo Latinoamericano de Ciencias Sociales (CLACSO).

Basualdo, E. (2007). Concepto de patrón o régimen de acumulación y conformación estructural de la economía. Documento de Trabajo № 1, Maestría en Economía Política Argentina, Facultad Latinoamericana de Ciencias Sociales (FLACSO). Buenos Aires: FLACSO.

Basualdo, E. (2010). Estudios de historia económica argentina. Desde mediados del siglo XX a la actualidad. Buenos Aires: Siglo XXI.

Basualdo, E. (2019). Fundamentos de economía política. Los patrones de acumulación, de los clásicos al neoliberalismo del siglo XXI. Buenos Aires: Siglo XXI.

Bonnet, A. (2008). La hegemonía menemista: el neoconservadurismo en Argentina, 1989-2001. Buenos Aires: Prometeo.

Bonnet, A. (2015). La insurrección como restauración. El kirchnerismo (2002-2015). Buenos Aires: Prometeo.

Bourdieu, P. y Wacquant, L. (2005). Una invitación a la sociología reflexiva. Buenos Aires: Siglo XXI.

Boyer, R. [1986] (1989). La teoría de la regulación. Un análisis crítico. Buenos Aires: Área de Estudios e Investigaciones Laborales de la SECyT / CEIL-CONICET / CREDAL-CNRS / Hvmanitas.

Boyer, R. (2007). Crisis y regímenes de crecimiento: una introducción a la teoría de la regulación. Buenos Aires: Miño y Dávila / CEIL-PIETTE-CONICET.

Boyer, R. y Neffa, J. C. (coords.). (2004). La economía argentina y sus crisis (19762001): visiones institucionalistas y regulacionistas. Buenos Aires: CEIL-PIETTECONICET / Miño y Dávila. 
Boyer, R. y Saillard, Y. (eds.) (1996). Teoría de la regulación: estado de los conocimientos, Vol. 1. Buenos Aires: Oficina de Publicaciones del CBC - Universidad de Buenos Aires / Asociación Trabajo y Sociedad.

Block, F. (1986). Political choice and multiple 'logics` of capital. Theory and Society, 15(1-2), 175-192.

Constantino, A. y Cantamutto, F. (2014). Patrón de reproducción del capital y clases sociales en la Argentina contemporánea. Sociológica, 29(81), 39-86.

Costa, A. (2010). La anatomía del nuevo patrón de crecimiento y la encrucijada actual: la economía argentina período 2002-2010. Buenos Aires: Atuel.

Gordon, D., Edwards, R. y Reich, M. (1982). Segmented Work, divided workers: the historical transformation of labor in the United States. New York: Cambridge University Press.

Gramsci, Antonio (1974). El Risorgimento. Buenos Aires: Granica.

Grigera, J. (2011). Desindustrialización, ¿Agresión a la manufactura o reestructuración capitalista? En A. Bonnet (comp.); El país invisible. Debates sobre la Argentina reciente. Buenos Aires: Continente.

Grigera, J. (2013). Esperando a EP Thompson. Desindustrialización y formación de clases sociales en Argentina (1976-2001). Revista Mundos do Trabalho, 5(10), 7188.

Jessop, R. (1983) Accumulation strategies and hegemonic projects. Kapitalistate, (10), 89-111.

Lechner, N. (1982). ¿Qué significa hacer política? Lima: Deseo.

Lechner, N. (1988). De la revolución a la democracia. En Los patios interiores de la democracia. Subjetividad y política. Santiago de Chile: FLACSO.

Leontief, W. (1985). Análisis económicos input-output. En La estructura del desarrollo. Barcelona: Orbis.

Lesgart, C. (2002). Usos de la transición a la democracia. Ensayo, ciencia y política en la década del ochenta. Estudios sociales. Revista Universitaria Semestral, XII(2223), 163-185.

Lesgart, C. (2004). Itinerarios conceptuales hacia la democracia. Una tendencia de la 
La categoría «régimen de acumulación»: límites y potencialidades para el estudio de la historia económica argentina. Hacia una propuesta para su reconceptualización

izquierda intelectual argentina en el exilio mexicano. En F. Devoto y N. Pagano (eds.); La historiografía académica y la historiografía militante en Argentina y Uruguay. Buenos Aires: Biblos.

Marx, K. [1867] (1975). El Capital. Crítica de la economía política. Libro Primero. El proceso de producción del capital. Tomo I, Vol. I. México: Siglo XXI.

Marx, K. [1859] (1980). Contribución a la crítica de la economía política. México: Siglo XXI.

Meiksins Wood, E. (1983). El concepto de clase en E. P. Thompson. Cuadernos Políticos, (36), 87-105.

Morón, S. y Caro, R. (2013). Régimen Social de Acumulación: historia política y económica de un concepto. En S. Morón y S. Roitman (comps.); Procesos de acumulación y conflicto social en la Argentina contemporánea: debates teóricos y estudios empíricos. Córdoba: Universitas.

Neffa, J. C. (1996). Crisis, régimen de acumulación y proceso de reconversión en la Argentina: un análisis desde la Teoría de la Regulación. Dialógica, 1(1), 261-323.

Neffa, J. C. (1998). Modos de regulación, regímenes de acumulación y sus crisis en Argentina (1880-1996). Buenos Aires: Eudeba / PIETTE-CONICET / Asociación Trabajo y Sociedad.

Neffa, J. C. (2004). La forma institucional relación salarial y su evolución en la Argentina desde una perspectiva de largo plazo. En R. Boyer y J. C. Neffa (coords.); La economía argentina y su crisis (1976-2001): visiones institucionalistas y regulacionistas. Buenos Aires: Miño y Dávila / Caisse de Depôts et Consignations / CEIL-PIETTE-CONICET.

Neffa, J. C. (2008). Evolución del modo de desarrollo argentino y su impacto sobre la relación salarial: un enfoque de largo plazo desde la teoría de la regulación. En J. C. Neffa y F. C. Toledo (coords.); Interpretaciones heterodoxas de las crisis económicas en Argentina y sus efectos sociales. Buenos Aires: Miño y Dávila / CEIL-PIETTECONICET.

Neffa, J. C. et al. (2010). Contribuciones al estudio del trabajo y el empleo desde la teoría de la regulación: un marco teórico para estudiar los modos de desarrollo y su impacto sobre el empleo. Documento de Trabajo № 4. Buenos Aires: CEIL-PIETTECONICET. 
Nogueira, M. E. (2010). Breves notas sobre el concepto régimen social de acumulación y su pertinencia actual. Revista Pilquen, XII(13), 1-10.

North, D. [1990] (1993). Instituciones, cambio institucional y desempeño económico. México: Fondo de Cultura Económica (FCE).

Nun, J. (1987a). La legitimidad democrática y los parecidos de familia. Notas preliminares. Revista Punto de Vista, X(31), 31-44.

Nun, J. (1987b). La teoría política y la tradición democrática. En J. Nun y J. C. Portantiero; Ensayos sobre la transición democrática en Argentina. Buenos Aires: Puntosur.

Nun, J. (1989). Algunas exploraciones teóricas en torno a las transiciones democráticas. En La rebelión del coro. Estudios sobre la racionalidad política y el sentido común. Buenos Aires: Nueva Visión.

Nun, J. (1995). Argentina: El estado argentino y las actividades científicas y tecnológicas. Redes. Revista de estudios sociales de la ciencia, 2(3), 59-98.

Nun, J. (2001a). Democracia ¿Gobierno del pueblo o gobierno de los políticos? Buenos Aires: FCE.

Nun, J. (2001b). Marginalidad y exclusión social. Buenos Aires: FCE.

Nun, J. y Portantiero, J. C. (comps.) (1987). Ensayos sobre la transición democrática en la Argentina. Buenos Aires: Puntosur.

O’Donnell, G. (1984). Apuntes para una teoría del Estado. En O. Oszlak (comp.); Teoría de la burocracia estatal. Buenos Aires: Paidós.

Osorio, J. (2014). Estado, reproducción del capital y lucha de clases. La unidad económico/política del capital. México: Instituto de Investigaciones Económicas Universidad Nacional Autónoma de México (UNAM).

Pérez Álvarez, G. (2013). Una discusión con el concepto de "desindustrialización" desde el caso del noreste de Chubut. Revista de Estudios Marítimos y Sociales, 5/6(5/6), 177-185.

Piva, A. (2012). Acumulación y hegemonía en la Argentina menemista. Buenos Aires: Biblos. 
La categoría «régimen de acumulación»: límites y potencialidades para el estudio de la historia económica argentina. Hacia una propuesta para su reconceptualización

Piva, A. (2015). Economía y política en la Argentina kirchnerista. Buenos Aires: Batalla de Ideas.

Portelli, H. (1980). Gramsci y el bloque histórico. Buenos Aires: Siglo XXI.

Poulantzas, N. (1976). Las clases sociales en América Latina. México: Siglo XXI.

Saiz Bonzano, S. (2011). Régimen social de acumulación. Estructura y acción al interior del conflicto capital-trabajo. Aportes para el estudio de la convertibilidad argentina. Saarbrücken: Académica Española.

Saiz Bonzano, S. (2012). Régimen Social de Acumulación: hacia una genealogía conceptual. Ponencia presentada en V Jornadas de Economía Crítica, Buenos Aires.

Sartelli, E. y Kabat, M. (2016). Argentine Industrialization: A Critique of the Liberal and Dependentist Schools. Research in political economy, (30), 227-254.

Schorr, M. y Wainer, A. (2017). Modelo de acumulación. Una aproximación conceptual. Revista Unidad Sociológica 3(10), 6-10.

Schumpeter, J. (1982). Historia del Análisis Económico. Barcelona: Ariel.

Svampa, M. (2011). Modelo de Desarrollo y cuestión ambiental en América Latina: categorías y escenarios en disputa. En F. Wanderley (comp.); El desarrollo en cuestión. Reflexiones desde América Latina. La Paz: CIDES / OXFAM / Plural.

Thompson, E. (1978). La formación de la clase obrera en Inglaterra. Barcelona: Guadamarra.

Torrado, S. (1992). Estructura Social de la Argentina: 1945-1983. Buenos Aires: Ediciones de La Flor.

Veyne, P. (1984). Cómo se escribe la historia. Foucault revoluciona la historia. Madrid: Alianza.

Williams, R. (1978). Marxismo y literatura. Barcelona: Península.

Recibido: $10 / 05 / 2019$

Evaluado: $14 / 06 / 2019$

Versión Final: 01/08/2019 
Julieta Almada - Federico Hernán Reche - Sergio Ramiro Saiz Bonzano 